\title{
Antibiotic resistance, virulence determinants and production of biogenic amines among enterococci from ovine, feline, canine, porcine and human milk
}

Esther Jiménez ${ }^{1}$, Victor Ladero², Irene Chico ${ }^{1}$, Antonio Maldonado-Barragán ${ }^{3}$, María López ${ }^{4}$, Virginia Martín ${ }^{1,5}$, Leonides Fernández ${ }^{1,5}$, María Fernández ${ }^{2}$, Miguel A Álvarez ${ }^{2}$, Carmen Torres ${ }^{4}$ and Juan M Rodríguez ${ }^{1,5^{*}}$

\begin{abstract}
Background: Recent studies have shown that mammalian milk represents a continuous supply of commensal bacteria, including enterococci. The objectives of this study were to evaluate the presence of enterococci in milk of different species and to screen them for several genetic and phenotypic traits of clinical significance among enterococci.

Results: Samples were obtained from, at least, nine porcine, canine, ovine, feline and human healthy hosts. Enterococci could be isolated, at a concentration of $1.00 \times 10^{2}-1.16 \times 10^{3} \mathrm{CFU} / \mathrm{ml}$, from all the porcine samples and, also from 85, 50, 25 and 25\% of the human, canine, feline and ovine ones, respectively. They were identified as Enterococcus faecalis, Enterococcus faecium, Enterococcus hirae, Enterococcus casseliflavus and Enterococcus durans. Among the 120 initial enterococcal isolates, 36 were selected on the basis of their different PFGE profiles and further characterized. MLST analysis revealed a wide diversity of STs among the E. faecalis and E. faecium strains, including some frequently associated to hospital infections and novel STs. All the E. faecalis strains possessed some of the potential virulence determinants (cad, ccf, cob, cpd, efaA $A_{f s}, a g g 2$, gelE, cylA, esp $f_{f s}$ ) assayed while the $E$. faecium ones only harboured the efa $A_{f m}$ gene. All the tested strains were susceptible to tigecycline, linezolid and vancomycin, and produced tyramine. Their susceptibility to the rest of the antimicrobials and their ability to produce other biogenic amines varied depending on the strain. Enterococci strains isolated from porcine samples showed the widest spectrum of antibiotic resistance.

Conclusions: Enterococci isolated from milk of different mammals showed a great genetic diversity. The wide distribution of virulence genes and/or antibiotic resistance among the E. faecalis and E. faecium isolates indicates that they can constitute a reservoir of such traits and a risk to animal and human health.
\end{abstract}

Keywords: Enterococcus, Milk, Mammals, Virulence, Antibiotic resistance, Biogenic amines

\footnotetext{
* Correspondence: jmrodrig@vet.ucm.es

'Departamento de Nutrición, Bromatología y Tecnología de los Alimentos,

Universidad Complutense de Madrid, Ciudad Universitaria, Avda. Puerta de Hierro, Madrid s/n. 28040, Spain

${ }^{5}$ Probisearch. c/Santiago Grisolía, Tres Cantos 2. 28760, Spain

Full list of author information is available at the end of the article
} 


\section{Background}

Natural lactation provides a wide variety of short- and long-term health benefits, being a critical period for mammals' growth and development; in fact, precocious weaning is associated with high mortality and morbidity rates, particularly in those species in which IgG transfer mainly occurs through maternal milk [1]. Fresh mammalian milk from a given species usually fulfils the nutritional requirements of the neonates of such species and, also, protects them against infectious diseases.

This protective effect is due to the combined action of a variety of protective factors present in colostrum and milk, such as immunoglobulins, immunocompetent cells, fatty acids, polyamines, oligosaccharides and peptides [2-5]. In addition, it has been recently shown that these biological fluids are the vehicle for a variety of commensal, mutualistic or potentially probiotic bacteria [6-11].

The mammalian milk microbiota seems dominated by staphylococci and streptococci [12-14] but it also contains lactic acid bacteria, including enterococci $[7,12,15,16]$. Enterococci become normal components of the mammalian gastro-intestinal tract soon after birth $[17,18]$. Some strains have even been proposed for the production of fermented foods or used as human and animal probiotics. However, enterococci are opportunistic pathogens that may cause a range of different infections in animals and humans, including urinary tract infections, mastitis, sepsis, and endocarditis, particularly in hosts with underlying diseases and in neonates [19-21]. Virulence, antibiotic resistance or gene transfer potential have been considered as strain-specific properties within enterococci $[22,23]$. Recently, genome sequencing of a high number of diverse Enterococcus faecium strains has been applied to resolve the lineage responsible for epidemic and/or multidrugresistant infections from other strains, and to measure the evolutionary distances between groups [24]. Such approach has shown that each evolutionary bifurcation has been accompanied by the acquisition of new metabolic and colonization traits on mobile elements and genome remodeling associated with the insertion and movement of such elements. As a result, diversity within such enterococcal species, in terms of sequence divergence as well as gene content, may span a range usually associated with speciation [24].

The use of antimicrobial agents in the modern farm industry has created a reservoir of resistant enterococci in food animals and in food of animal origin [25,26]; these enterococci are likely to contribute resistance and virulence-associated genes to enterococci inhabiting pets and human hosts since such genes appear to spread freely between enterococci from different reservoirs, irrespective of their apparent host association [27,28]. Moreover, enterococci are one of the groups of bacteria mainly responsible for the accumulation of biogenic amines (BAs) -especially tyramine and putrescine- in fermented dairy foods. BAs are nitrogenous compounds formed by amino acid decarboxilation, with important physiological functions in mammals, as brain activity, immune response, cell growth and differentiation, etc. However, the consumption of food contaminated with BAs provokes several toxic effects, particularly in people who have impaired the detoxification system [29].

Since milk constitute one of the first sources of enterococci to the mammalian gut, the objectives of this study were, first, to evaluate the presence of enterococci in milk of healthy hosts belonging to different mammals' species, including food animal species (sow, ewe), pets (bitches, queens) and women, and, subsequently, to screen them for several genetic and phenotypic traits of clinical significance among enterococci.

\section{Methods}

\section{Source and isolation of bacterial isolates}

Milk samples were obtained from porcine (intensive farming), canine, ovine (extensive farming), feline and human hosts (Table 1) living in the same geographical area and that fulfilled the following criteria: (a) healthy individuals without present or past underlying conditions; (b) normal pregnancy; and (c) absence of perinatal problems in the mother and in the infant/offspring. For each species, a total of 8 samples (from different individuals) were collected, with the exception of porcine milk (9 samples). The protocol for milk collection from the animals was approved by the Ethical Committee on Animal Experimentation of Universidad Complutense de Madrid (Spain) and, in addition, all the animals' owners gave their consent to sampling and analysis. All human volunteers gave written informed consent to sample collection and analysis, which were approved by the Ethical Committee of Hospital Clínico of Madrid (Spain).

Milk samples ( $\sim 5 \mathrm{ml}$ from sows, ewes and women; $\sim 3 \mathrm{ml}$ from the remaining species) were collected in sterile tubes by manual expression using sterile gloves. Previously, nipples and surrounding skin were cleaned with soap and sterile water, and soaked in chlorhexidine (Cristalmina, Salvat, Barcelona, Spain). The first drops $(\sim 1 \mathrm{ml})$ were discarded. The milk samples were obtained at day 7 after delivery and kept at $4^{\circ} \mathrm{C}$ until delivery to the laboratory, which happened within the first three hours after collection.

Samples (the original samples but, also, three serial decimal dilutions of each one in peptone water) were plated $(100 \mu \mathrm{l})$ in triplicate onto Kanamycin Esculin Azide (KAA, Oxoid, Basingstoke, UK) agar plates. Parallel, and to evaluate potential faecal contamination, the samples were also cultured on Violet Red Bile Agar (VRBA; Difco, Detroit, MI) agar plates; all the plates were aerobically incubated at $37^{\circ} \mathrm{C}$ for $24 \mathrm{~h}$. In both 
Table 1 Enterococcal concentration (CFU/ml) in milk samples of different mammalian and strains isolated from each sample

\begin{tabular}{|c|c|c|c|c|c|c|c|}
\hline Species & Sample & Concentration & E. faecalis & E. faecium & E. durans & E. hirae & E. casseliflavus \\
\hline \multirow[t]{13}{*}{ Porcine } & P1 & $8.00 \times 10^{2}$ & ECA3 & ECA2B & - & - & - \\
\hline & P2 & $9.02 \times 10^{2}$ & ECB1 & ECB4 & - & - & - \\
\hline & P3 & $1.16 \times 10^{3}$ & ECC5 & ECC2A & - & ECC1 & - \\
\hline & P4 & $1.04 \times 10^{3}$ & $\mathrm{ECD} 1^{\mathrm{a}}$ & ECD3 & - & - & - \\
\hline & & & ECD2 & & & & \\
\hline & P5 & $8.38 \times 10^{2}$ & $\mathrm{ECE} 1^{\mathrm{a}}$ & - & - & - & - \\
\hline & P6 & $8.72 \times 10^{2}$ & - & ECF2 & - & - & - \\
\hline & & & & ECF5 & & & \\
\hline & P7 & $9.46 \times 10^{2}$ & $\mathrm{ECG} 2^{\mathrm{b}}$ & - & - & ECG1 & - \\
\hline & P8 & $8.68 \times 10^{2}$ & $\mathrm{ECH} 1^{\mathrm{C}}$ & - & - & - & - \\
\hline & & & $\mathrm{ECH} 6$ & & & & \\
\hline & P9 & $8.28 \times 10^{2}$ & $\mathrm{ECl1}{ }^{\mathrm{b}}$ & - & - & - & - \\
\hline & & & $\mathrm{ECl}^{\mathrm{C}}$ & & & & \\
\hline \multirow[t]{4}{*}{ Canine } & $\mathrm{C} 1$ & $3.02 \times 10^{2}$ & PKG12 & - & - & - & - \\
\hline & $C 2$ & $2.58 \times 10^{2}$ & PRA5 & - & - & - & - \\
\hline & C3 & $2.62 \times 10^{3}$ & - & PGAH11 & - & - & - \\
\hline & C4 & $1.24 \times 10^{2}$ & - & PKB4 & - & - & - \\
\hline \multirow[t]{3}{*}{ Ovine } & 01 & $7.22 \times 10^{2}$ & EOA1 & - & - & EOA2 & - \\
\hline & $\mathrm{O} 2$ & $8.00 \times 10^{2}$ & EOB6A & - & - & - & EOB3 \\
\hline & & & & & & & EOB5 \\
\hline \multirow[t]{2}{*}{ Feline } & F1 & $6.20 \times 10^{2}$ & - & - & - & EH11 & - \\
\hline & $\mathrm{F} 2$ & $5.14 \times 10^{2}$ & G8-1 K & - & - & - & - \\
\hline \multirow[t]{7}{*}{ Human } & $\mathrm{H} 1$ & $1.00 \times 10^{2}$ & - & - & C2341 & - & - \\
\hline & $\mathrm{H} 2$ & $1.22 \times 10^{2}$ & - & - & C1943 & - & - \\
\hline & $\mathrm{H} 3$ & $2.12 \times 10^{2}$ & C1252 & - & - & - & - \\
\hline & $\mathrm{H} 4$ & $1.66 \times 10^{2}$ & C901 & - & - & - & - \\
\hline & $\mathrm{H} 5$ & $1.54 \times 10^{2}$ & - & C656 & - & - & - \\
\hline & $\mathrm{H} 6$ & $2.32 \times 10^{2}$ & - & - & C654 & - & - \\
\hline & $\mathrm{H} 7$ & $2.16 \times 10^{2}$ & - & - & C502 & - & - \\
\hline TOTAL & 29 & & $15^{d}$ & 9 & 4 & 4 & 2 \\
\hline
\end{tabular}

asolates ECD1 and ECE1 are identical; ${ }^{b}$ Isolates ECG2 and ECI1 are identical; ${ }^{\mathrm{c}}$ Isolates $\mathrm{ECH} 1$ and $\mathrm{ECl} 3$ are identical. ${ }^{\mathrm{d}}$ Number of different $E$. faecalis strains.

growth media, the lower limit of detection was $10 \mathrm{CFU}$ (colony-forming units)/ml.

\section{Identification of bacterial isolates}

The potential enterococal isolates (black colonies growing on KAA agar) were observed by optical microscopy to determine their morphology and Gram staining. Additionally, they were tested for catalase, oxidase and coagulase activities. A single colony of each isolate was suspended in $20 \mu \mathrm{l}$ of deionized sterile water; $5 \mu \mathrm{l}$ of the suspension were used as a template for species identification by PCR. First, the gene $d d l$, which encode D-alanine:D-alanine ligases, was used as target following the protocol previously described by Dutka-Malen et al.
[30]. The pair of primers E1 (5'-ATCAAGTACAGT TAGTCTT-3')/E2 (5'-ACGATTCAAAGCTAACTG-3'), allowed to identify E. faecium strains, while the second pair F1 (5'-GCAAGGCTTCTTAGAGA-3')/ F2 (5' -CATCGTGTAAGCTAACTTC-3') is specific for Enterococcus faecalis. Identification of the rest of isolates was performed by sequencing the $470 \mathrm{pb}$ fragment of the $16 \mathrm{~S}$ rDNA gene PCR amplified using the primers pbl16 (5'-AGAGTTTGATCCTGGCTCAG-3') and mbl16 (5'GGCTGCTGGCACGTAGTTAG-3') [31]. The PCR conditions were as follows: $96^{\circ} \mathrm{C}$ for $30 \mathrm{~s}, 48^{\circ} \mathrm{C}$ for $30 \mathrm{~s}$ and $72^{\circ} \mathrm{C}$ for $45 \mathrm{~s}$ ( 40 cycles) and a final extension at $72^{\circ} \mathrm{C}$ for $4 \mathrm{~min}$. The amplicons were purified using the Nucleospin ${ }^{\circ}$ Extract II kit (Macherey-Nagel, Düren, Germany) and 
sequenced at the Genomics Unit of the Universidad Complutense de Madrid, Spain. The resulting sequences were used to search sequences deposited in the EMBL database using BLAST algorithm and the identity of the isolates was determined on the basis of the highest scores $(>99 \%)$.

\section{Genetic profiling of the enterococcal isolates}

Initially, the enterococcal isolates were typed by Random Amplification of Polymorphic DNA (RAPD) in order to avoid duplication of isolates from a same host. RAPD profiles were obtained using primer OPL5 (5'-ACGCAGG CAC-3'), as described by Ruíz-Barba et al. [32]. Later, a representative of each RAPD profile found in each host was submitted to PFGE genotyping [33]; for this purpose, chromosomal DNA was digested with the endonuclease SmaI (New England Biolabs, Ipswich, MA) at $37^{\circ} \mathrm{C}$ for $16 \mathrm{~h}$. Then, electrophoresis was carried out in a CHEF DR-III apparatus (Bio-Rad) for $23 \mathrm{~h}$ at $14^{\circ} \mathrm{C}$ at $6 \mathrm{~V} / \mathrm{cm}$ with pulses from 5 to $50 \mathrm{~s}$. A standard pattern (Lamda Ladder PFG Marker, New England Biolabs) was included in the gels to compare the digitally normalized PFGE profiles. Computer-assisted analysis was performed with the Phoretix 1D Pro software (Nonlinear USA, Inc., Durham, NC).

\section{Multilocus sequence typing (MLST)}

Molecular typing of E. faecalis and E. faecium isolates was performed by MLST. Internal fragments of seven housekeeping genes of E. faecalis ( $g d h, g y d, p s t S, g k i$, aroE, xpt and yiqL) and E. faecium (atpA, ddl, gdh, purK, gyd, pstS, and $a d k$ ) were amplified and sequenced. The sequences obtained were analyzed and compared with those included in the website database (http://efaecalis.mlst.net/), and a specific sequence type (ST) and clonal complex (CC) was assigned [34,35].

\section{Screening for virulence determinants, hemolysis and gelatinase activity}

A multiplex PCR method [15] was used to detect the presence of virulence determinants encoding sex pheromones (ccf, cpd, $c a d, c o b)$, adhesins $\left(e f a_{A f s}, e f a_{A f m}\right)$, and products involved in aggregation (agg2), biosynthesis of an extracellular metalloendopeptidase ( $(\mathrm{elE})$ ), biosynthesis of cytolysin $(c y l A)$ and immune evasion $\left(e s p_{\mathrm{fs}}\right)$. The primers couples used to detect all the genes cited above were those proposed by Eaton and Gasson [22]. The presence of the hyl gene (encoding a glycosyl hydrolase) and IS16 (potential marker of hospital associated E. faecium strains) was also checked by PCR among E. faecium strains as described previously [36,37]. Control strains used in PCR experiments were $E$. faecalis strains F4 $\left(e f a A_{f s}+g e l E+\right.$ $a g g+c y l M B A+e s p+c p d+c o b+c c f+c a d+), \mathrm{P} 36\left(e f a A_{f s}+\right.$ $g e l E+a g g+c y l A+e s p+c p d+c o b+c c f+c a d+)$ and $\mathrm{P} 4$ $\left(e f a A_{f s}+g e l E+a g g+c y l A+c p d+c o b+c c f+c a d+\right)$, E. faecium P61 (efaAfm + esp+) and E. faecium C2302 (hyl). PCR conditions were as follows: initial denaturation at $94^{\circ} \mathrm{C}$ for $5 \mathrm{~min}$; 30 cycles of denaturation at $94^{\circ} \mathrm{C}$ for $1 \mathrm{~min}$, annealing at $51^{\circ} \mathrm{C}$ for $30 \mathrm{~s}$ and elongation at $72^{\circ} \mathrm{C}$ for $1.5 \mathrm{~min}$, and a final extension at $72^{\circ} \mathrm{C}$ for $5 \mathrm{~min}$.

Haemolysin activity was evaluated on Columbia Blood Agar (Oxoid) containing 5\% defibrinised horse blood. Single colonies were streaked onto plates and incubated at $37^{\circ} \mathrm{C}$ for $24 \mathrm{~h}$. Zones of clearing around colonies indicated haemolysin production.

Production of gelatinase was determined on tryptic soy agar plates (Oxoid) supplemented with $3 \%$ gelatin. Plates streaked with the strains were incubated at $37^{\circ} \mathrm{C}$ for $24 \mathrm{~h}$, and cooled at $4^{\circ} \mathrm{C}$ for $4 \mathrm{~h}$. A clear halo around colonies was considered to be positive indication of gelatinase activity.

\section{Capacity to produce biogenic amines}

The presence of the tyrosine decarboxylase gene $(t d c A)$, histidine decarboxylase gene $(h d c A)$ and agmatine deiminase cluster $(A g d D I)$ was checked by specific PCR using the primers pairs P2-for and P1-rev [38], JV16HC and JV17HC [39], and PTC2 and AgdDr [40], respectively. PCR conditions were those described by the respective authors. Total DNA, obtained as described by [32], was used as template. E. faecalis V583, which produce putrescine and tyramine, and Lactobacillus buchneri B301, which produce histamine, were used as positive controls.

The enterococcal strains were grown for $24 \mathrm{~h}$ in M17 broth supplemented with $10 \mathrm{mM}$ tyrosine (M17T), $13 \mathrm{mM}$ of histidine (M17H) or $20 \mathrm{mM}$ agmatine (M17A) for the detection of tyramine, histamine and putrescine production, respectively. The supernatants were filtered through a $0.2 \mu \mathrm{m}$ pore diameter membrane, derivatyzed and analysed by thin layer chromatography (TLC) following the conditions described by García-Moruno et al. [41].

\section{Susceptibility to antibiotics}

Minimum inhibitory concentrations (MICs) of 12 antimicrobial agents (ampicillin, gentamicin, streptomycin, quinupristin/dalfopristin, kanamycin, erythromycin, clindamycin, oxytetracycline, chloramphenicol, tigecycline, linezolid and vancomycin) were determined by the E-test (AB BIODISK, Solna, Sweden) following the instructions of the manufacturer. The E-test strips contained preformed antimicrobial gradients in the test range from 0.016 to $256 \mu \mathrm{g} / \mathrm{ml}$ for tetracycline, erythromycin, gentamicin, kanamycin, clindamycin, ampicillin, chloramphenicol, tigecycline, linezolid and vancomycin, from 0.064 to $1.024 \mu \mathrm{g} / \mathrm{ml}$ for streptomycin, and from 0.002 to $32 \mu \mathrm{g} / \mathrm{ml}$ for quinupristin-dalfopristin. Results from the different antibiotic susceptibility tests were interpreted according to 
the cut-off values and clinical breakpoints proposed by the European Committee on Antimicrobial Susceptibility Testing (EUCAST) while the breakpoints of the Clinical and Laboratory Standards Institute (CLSI) [42] were used for those antibiotics not included in EUCAST.

\section{Screening for van genes}

PCR reactions for $v a n A$ and $v a n B$ genes were performed as described previously [30,43]. Oligonucleotides used as primers for the amplification of the $732 \mathrm{bp}$ fragment of the vanA gene were VanA1 (5'-GGGAAAACGACAATT GC-3') and VanA2 (5'-GTACAATGCGGCCGTTA-3'), while those used for amplification of the 1,145 bp fragment of $v a n B$ were VanBfor (5'-GTGCTGCGAGATAC CACAGA-3') and VanBrev (5'-CGAACACCATGCAA CATTTC'). E. faecium BM4147 (resistant to vancomycin, $\mathrm{VanA}+$ ) and $E$. faecalis V583 (resistant to vancomycin, $\mathrm{VanB}+$ ) were used as positive controls. PCR assays for the detection of $v a n D, v a n E$ and $v a n G$ genes in the enterococcal isolates was performed as previously described [44-46].

\section{Results}

Isolation, identification and profiling of the enterococcal isolates

Colonies were obtained from all the porcine and 7 out of 8 human samples when inoculated onto KAA plates. In contrast, colonies could be isolated from $50 \%$ of the canine samples and only from $25 \%$ of the feline and ovine ones (Table 1). When bacterial growth was detected, the KAA counts ranged from $1.00 \times 10^{2}$ to $1.16 \times 10^{3} \mathrm{CFU} / \mathrm{ml}$ (Table 1). No colonies were detected on VRBA plates, which confirmed the hygienic collection of the milk samples.

Five isolates showing a coccoid shape and catalasenegative and oxidase-negative reactions were randomly selected from each sample in which colonies were observed. The 120 isolates were identified to the species level as E. faecalis, E. faecium, Enterococcus hirae, Enterococcus casseliflavus or Enterococcus durans (Table 1). Among them, E. faecalis isolates were the most abundant and, in addition, this was the only enterococcal species present in samples from all the mammalians' species included in this study. E. faecium was found in canine, swine and human milk samples but not in the ovine or feline ones. E. hirae was present in ovine, swine and feline milk samples. Finally, E. casseliflavus and E. durans could be isolated only from ovine and human milk samples, respectively. There was a maximum of three different enterococcal species in a same sample (porcine sample no. P3: E. faecalis, $E$. faecium and $E$. hirae), while only one enterococcal species was detected in each of the canine, feline and human samples (Table 1).

RAPD and PFGE profiling revealed that, for each enterococcal species, there was a single strain per sample, with the exception of four porcine and one ovine samples (Table 1). PFGE genotyping also revealed that three $E$. faecalis strains were shared by different porcine samples (Table 1). Based on their different PFGE profiles, 36 enterococcal isolates from milk of the 5 mammalian species were selected subsequently, for further characterization.

\section{MLST analysis of the E. faecalis and E. faecium strains}

MLST analysis of the E. faecalis strains revealed the occurrence of 8 different STs, including one novel ST (ST473) from a canine sample (Table 2). The most frequent clones were ST16, which was found among 4 strains (all of them from porcine origin), and ST9, which was detected among 3 strains (one porcine strain and the two ovine ones). Clone ST200 was shared by two porcine strains while clone ST21 was shared by one porcine and the feline strain.

MLST analysis was also performed with the 9 E. faecium strains recovered from the different origins. Eight different STs were detected among E. faecium strains, five of them known (ST5, ST30, ST183, ST272, ST442 and ST654), and two new STs that presented new allelic combinations (ST882 and ST883, of porcine origin). For one of the E. faecium strains it was not possible to determine the ST (Table 3).

\section{Occurrence of putative virulence genes}

None of the potential virulence determinants ( $c a d, c c f$, $c o b, c p d, e f a A_{f s}, e f a A_{f m}, a g g 2, g e l E, c y l A, e s p_{f s}$ ) tested in this study could be detected in any of the $E$. durans, $E$. hirae or E. casseliflavus strains. The E. faecium strains only harboured the $e f a A_{f m}$ gene, while all the E. faecalis strains possessed some potential virulence determinants (Table 2). Sex pheromones determinants (ccf, cpd, cad, $c o b)$ and the adhesin gene $e f a A_{f s}$ were detected in all $E$. faecalis strains, whereas the rest of the genes were variable on the strains. The $c y l A$ gene was not detected in any of the E. faecalis strains isolated from human, canine and feline milk. All E. faecium strains were negative for the $h y l$ gene and the IS16 element.

There was a good correlation between presence of gelE gene and gelatinase activity and, also, between presence of cylA gene and hemolytic activity (Table 2).

\section{Production of biogenic amines}

All the tested strains were positive for the $t d c$ gene and were able to produce tyramine (Table 4). In contrast, none of them harbored the $h d c$ gene and histamine was accordingly not detected in the cultures (Table 4). All the $E$. faecalis strains contained the genes involved in putrescine biosynthesis and produced putrescine in broth cultures, while the results were negative for the two E. casseliflavus strains. The ability to produce putrescine was variable in the other enterococcal species 
Table 2 MLST typing, presence of virulence determinants and hemolytic and gelatinase activities among the $E$. faecalis strains

\begin{tabular}{|c|c|c|c|c|c|c|c|c|c|c|c|c|c|}
\hline Origin & Strain & $\mathrm{ST}^{\mathrm{a}}$ & cad & $c c f$ & $c o b$ & cpd & $e f a A_{f s}$ & $e s p_{f s}$ & $a g g_{2}$ & gelE & cylA & Gelatinase & Hemolysis \\
\hline \multirow[t]{8}{*}{ Porcine } & ECA3 & ST21 & + & + & + & + & + & + & - & + & - & + & - \\
\hline & ECB1 & ST9 & + & + & + & + & + & + & + & + & + & + & + \\
\hline & ECC5 & ST16 & + & + & + & + & + & + & + & + & + & + & + \\
\hline & ECD2 & ST16 & + & + & + & + & + & + & + & - & + & - & + \\
\hline & ECE1 & ST200 & + & + & + & + & + & + & + & + & - & + & - \\
\hline & ECH6 & ST16 & + & + & + & + & + & + & + & - & + & - & + \\
\hline & $\mathrm{ECl} 1$ & ST200 & + & + & + & + & + & + & + & + & - & + & - \\
\hline & $\mathrm{ECl} 3$ & ST16 & + & + & + & + & + & + & + & + & + & + & + \\
\hline \multirow[t]{2}{*}{ Canine } & PKG12 & ST239 & + & + & + & + & + & - & - & + & - & + & - \\
\hline & PRA5 & ST473 & + & + & + & + & + & - & - & + & - & + & - \\
\hline \multirow[t]{2}{*}{ Ovine } & EOA1 & ST9 & + & + & + & + & + & + & + & + & + & + & + \\
\hline & EOB6A & ST9 & + & + & + & + & + & + & + & + & + & + & + \\
\hline Feline & G8-1 K & ST21 & + & + & + & + & + & - & + & + & - & - & - \\
\hline \multirow[t]{2}{*}{ Human } & C1252 & ST8 & + & + & + & + & + & + & - & + & - & + & - \\
\hline & C901 & ST30 & + & + & + & + & + & + & + & + & - & + & - \\
\hline Total & 15 & 15 & 15 & 15 & 15 & 15 & 15 & 12 & 11 & 13 & 7 & 12 & 7 \\
\hline Percentage & & & 100 & 100 & 100 & 100 & 100 & 80 & 73 & 87 & 47 & 80 & 47 \\
\hline
\end{tabular}

asT obtained by MLST typing.

(E. faecium, E. durans and E. hirae), having found both producing and non-producing strains (Table 4). There were only two strains -both belonging to E. hirae- in which the gene $(a g d D I)$ was present, but the production of the corresponding biogenic amine (putrescine) was not detected.

Antibiotic susceptibility and screening for van genes All the enterococcal strains showed susceptibility to tigecycline, linezolid and vancomycin, and exhibited high resistance to kanamycin. Their susceptibility to the rest of the antimicrobials included in this study is shown in Table 5. Most E. faecalis, E. faecium and E. hirae strains were resistant to tetracycline and chloramphenicol. All E. faecalis strains showed susceptibility to ampicillin whereas an important number of strains showed resistance to the rest of antibiotics tested. The strains identified as E. faecium and E. hirae did not present high-level resistance to gentamicin but exhibited high resistance rate towards the rest of antibiotics. Globally, E. casseliflavus

Table 3 MLST typing of the $E$. faecium strains

\begin{tabular}{|c|c|c|c|c|c|c|c|c|c|}
\hline \multirow[b]{2}{*}{ Origin } & \multirow[b]{2}{*}{ Strain } & \multicolumn{7}{|c|}{ Allele } & \multirow[b]{2}{*}{$\mathrm{ST}^{\mathrm{a}}$} \\
\hline & & $\operatorname{atp} A$ & $d d l$ & $g d h$ & purk & gyd & pstA & $a d k$ & \\
\hline \multirow[t]{6}{*}{ Porcine } & ECA2B & 5 & 5 & 1 & 9 & 1 & 1 & 1 & ST882 ${ }^{b}$ \\
\hline & ECB4 & 5 & 2 & 1 & 9 & 1 & 1 & 5 & ST5 (CC5) \\
\hline & ECC2A & 4 & 5 & 8 & 3 & 1 & 20 & 1 & ST272 (singleton) \\
\hline & ECD3 & 4 & 5 & 9 & 3 & 1 & 20 & 1 & ST183 \\
\hline & ECF2 & 9 & 4 & 12 & 3 & 1 & 20 & 1 & ST $883^{b}$ \\
\hline & ECF5 & 49 & 4 & - & - & - & 20 & 8 & $N T^{c}$ \\
\hline \multirow[t]{2}{*}{ Canine } & PGAH11 & 5 & 1 & 1 & 2 & 6 & 1 & 1 & ST442 \\
\hline & PKB4 & 5 & 3 & 1 & 6 & 2 & 2 & 1 & ST30 (singleton) \\
\hline Human & C656 & 8 & 8 & 8 & 23 & 1 & 27 & 15 & ST654 \\
\hline
\end{tabular}


Table 4 Detection of gene determinants for the biosynthesis of biogenic amines and production among the enterococcal isolates

\begin{tabular}{|c|c|c|c|c|c|c|}
\hline \multirow[b]{2}{*}{ Origin } & \multirow[b]{2}{*}{ Species } & \multirow[b]{2}{*}{ Strain } & \multirow[b]{2}{*}{ Tyramine $^{a}$} & \multirow[b]{2}{*}{ Histamine $^{b}$} & \multicolumn{2}{|c|}{ Putrescine } \\
\hline & & & & & Gene cluster & Production \\
\hline \multirow[t]{8}{*}{ Porcine } & E. faecalis & ECA3 & + & - & + & + \\
\hline & & ECB1 & + & - & + & + \\
\hline & & ECC5 & + & - & + & + \\
\hline & & ECD2 & + & - & + & + \\
\hline & & ECE1 & + & - & + & + \\
\hline & & $\mathrm{ECH} 6$ & + & - & + & + \\
\hline & & $\mathrm{ECl} 1$ & + & - & + & + \\
\hline & & $\mathrm{ECl} 3$ & + & - & + & + \\
\hline \multirow[t]{2}{*}{ Canine } & & PKG12 & + & - & + & + \\
\hline & & PRA5 & + & - & + & + \\
\hline \multirow[t]{2}{*}{ Ovine } & & EOA1 & + & - & + & + \\
\hline & & EOB6A & + & - & + & + \\
\hline Feline & & G8-1 K & + & - & + & + \\
\hline \multirow[t]{2}{*}{ Human } & & $\mathrm{C} 1252$ & + & - & + & + \\
\hline & & C901 & + & - & + & + \\
\hline \multirow[t]{6}{*}{ Porcine } & E. faecium & ECA2B & + & - & + & + \\
\hline & & ECB4 & + & - & + & + \\
\hline & & ECC2A & + & - & - & - \\
\hline & & ECD3 & + & - & - & - \\
\hline & & ECF2 & + & - & - & - \\
\hline & & ECF5 & + & - & - & - \\
\hline \multirow[t]{2}{*}{ Canine } & & PGAH11 & + & - & - & - \\
\hline & & PKB4 & + & - & - & - \\
\hline Human & & C656 & + & - & - & - \\
\hline \multirow[t]{4}{*}{ Human } & E. durans & C2341 & + & - & + & + \\
\hline & & C1943 & + & - & + & + \\
\hline & & C654 & + & - & - & - \\
\hline & & C502 & + & - & - & - \\
\hline \multirow[t]{2}{*}{ Porcine } & E. hirae & ECC1 & + & - & - & - \\
\hline & & ECG1 & + & - & + & - \\
\hline Ovine & & $\mathrm{EOA} 2$ & + & - & + & + \\
\hline Feline & & EH11 & + & - & + & - \\
\hline \multirow[t]{2}{*}{ Ovine } & E. casseliflavus & EOB3 & + & - & - & - \\
\hline & & EOB5 & + & - & - & - \\
\hline
\end{tabular}

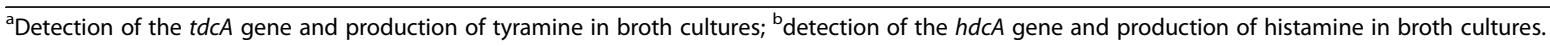

was the species with a highest susceptibility to the antibiotics tested followed by $E$. durans.

In relation with the milk origin, Enterococcus strains isolated from porcine samples showed the widest spectrum of antibiotic resistance and all the E. faecalis strains from such origin displayed resistance to, at least, six of the ten antibiotics tested (Table 5).
Finally, van genes could not detected in any Enterococcus strains studied in this work.

\section{Discussion}

Enterococci are common inhabitants of the gastrointestinal tract of humans and a wide variety of animals. In this study, the presence of enterococci in milk samples 
Table 5 Resistance (+) or susceptibility (-) of the enterococcal isolates against clinically-relevant antibiotics ${ }^{\mathrm{a}}$

\begin{tabular}{|c|c|c|c|c|c|c|c|c|c|c|}
\hline \multirow[b]{2}{*}{ Origin } & \multirow[b]{2}{*}{ Species } & \multirow[b]{2}{*}{ Strain } & \multicolumn{8}{|c|}{ Antibiotic $^{\mathrm{b}}$} \\
\hline & & & $\mathrm{AM}$ & GM & SM & EM & $\mathrm{CL}$ & QD & $\mathrm{TC}$ & $\mathrm{CM}$ \\
\hline \multirow[t]{8}{*}{ Porcine } & E. faecalis & ECA3 & - & - & + & + & - & + & + & + \\
\hline & & ECB1 & - & - & + & - & + & + & + & + \\
\hline & & ECC5 & - & + & + & + & - & + & + & + \\
\hline & & ECD2 & - & + & + & + & - & + & + & + \\
\hline & & ECE1 & - & - & + & + & + & + & + & + \\
\hline & & $\mathrm{ECH} 6$ & - & + & + & + & - & + & + & + \\
\hline & & ECl1 & - & - & + & + & + & + & + & + \\
\hline & & $\mathrm{ECl} 3$ & - & + & + & + & - & + & + & + \\
\hline \multirow[t]{2}{*}{ Canine } & & PKG12 & - & - & + & - & - & - & - & + \\
\hline & & PRA5 & - & - & + & - & + & + & - & + \\
\hline \multirow[t]{2}{*}{ Ovine } & & EOA1 & - & - & + & - & + & + & + & + \\
\hline & & EOB6A & - & - & + & - & + & + & + & + \\
\hline Feline & & G8-1 K & - & - & + & - & + & + & - & + \\
\hline \multirow[t]{2}{*}{ Human } & & C1252 & - & + & + & - & - & + & + & + \\
\hline & & C901 & - & + & + & - & - & + & + & + \\
\hline \multirow[t]{6}{*}{ Porcine } & E. faecium & ECA2B & + & - & + & + & - & - & + & + \\
\hline & & ECB4 & - & - & + & - & + & + & + & + \\
\hline & & ECC2A & + & - & + & + & - & + & + & + \\
\hline & & ECD3 & - & - & + & - & + & - & + & + \\
\hline & & ECF2 & + & - & + & + & - & + & + & + \\
\hline & & ECF5 & - & - & + & + & - & + & + & + \\
\hline \multirow[t]{2}{*}{ Canine } & & PGAH11 & - & - & + & + & - & - & + & + \\
\hline & & PKB4 & - & - & + & - & - & - & + & - \\
\hline Human & & C656 & - & - & - & - & - & + & - & + \\
\hline \multirow[t]{4}{*}{ Human } & E. durans & $C 2341$ & - & - & - & - & - & - & - & - \\
\hline & & C1943 & - & - & + & - & - & + & - & + \\
\hline & & C654 & - & - & - & - & - & - & - & - \\
\hline & & C502 & + & + & - & + & + & - & - & + \\
\hline \multirow[t]{2}{*}{ Porcine } & E. hirae & ECC1 & + & - & - & - & - & - & + & + \\
\hline & & ECG1 & + & - & - & + & - & - & + & + \\
\hline Ovine & & EOA2 & + & - & - & + & + & + & + & + \\
\hline Feline & & EH11 & - & - & - & - & - & + & + & + \\
\hline \multirow[t]{2}{*}{ Ovine } & E. casseliflavus & EOB3 & - & - & - & - & - & + & - & + \\
\hline & & EOB5 & - & - & - & - & - & - & - & - \\
\hline
\end{tabular}

${ }^{a}$ All the enterococcal strains showed susceptibility to tigecycline, linezolid and vancomycin, and exhibited high resistance to kanamycin.

${ }^{b} \mathrm{AM}$ : ampicillin; GM: gentamicin; SM: streptomycin; EM: erythromycin; CL: clindamycin; QD: quinupristin/dalfopristin; TC: tetracycline; CM: chloramphenicol.

obtained from different mammalian species was investigated. Enterococci were isolated from all the porcine milk samples and from 7 out of 8 human samples, while they were less frequent in the canine, ovine and feline samples. All the strains were identified as E. faecalis, E. faecium, E. hirae, E. casseliflavus or E. durans. The number of different species in each milk sample was low, ranging from 1 to 3 . Similarly, the number of strains was also low and, in fact, each of the canine and human samples contained only one enterococcal strain. PFGE profiling revealed that only some of the porcine samples shared a given strain, which indicates that spread is facilitated in intensive farming settings.

Globally, the results showed that milk from different mammalian species may contain enterococci and, therefore, may constitute a natural source of such microorganisms 
for the infant/offspring. The KAA counts $(<1.16 \times$ $10^{3} \mathrm{CFU} / \mathrm{mL}$ ) were similar to those reported for hygienically-obtained human milk on MRS plates, a medium also suitable for isolation of enterococci [6,7]. As previously reported for lactobacilli in porcine and canine milk $[8,9]$, the enterococcal pattern observed in the milk samples seems to be restricted to a low number of species and strains, and also to have a high degree of individual variability. To our knowledge, this is the first description of enterococci isolated from fresh milk of healthy canine, feline and porcine hosts. Some E. faecium and E. faecalis strains from colostrum and milk of healthy women have been described previously [14-16,47]. In relation to ewe's milk, a pilot study showed that enterococci were present in excess of $2 \times 10^{2} \mathrm{CFU} / \mathrm{ml}$ in $15 \%$ of the samples of unpasteurized milk from goats and ewes in England and Wales [48]. Other study focused on the identification of indigenous lactic acid bacteria in four samples of fresh ewe's raw milk and four samples of derived artisanal cheese from Argentina revealed that $48 \%$ and 59\%, respectively, of the isolates obtained belonged to the genus Enterococcus [49].

The E. faecalis strains analyzed in this work possessed some potential virulence determinants, including all the sex pheromone determinants, but the gene encoding cytolysin $(c y l A)$ could only be detected in 7 strains. The results for the rest of the enterococcal genes were variable depending on the strains. On the other hand, only the $e f a A_{f m}$ gene could be detected among the E. faecium isolates. These results are similar to those obtained in previous studies with enterococcal strains isolated from human colostrum and milk [14-16]. The role of adhesin $E f a A_{f m}$ in virulence has not yet been demonstrated, in contrast to the Esp surface protein. In the absence of other virulence determinants, presence of $e f a A_{f m}$ seems to have no value as a risk indicator since this gene was also found in $100 \%$ of starter E. faecium strains with a long record of safe use in food [22]. The results also agree with those obtained in other studies focused on foodborne enterococci in the sense that $E$. faecalis strains harbor multiple virulence determinants with a much higher incidence than in other enterococcal species [23].

A great diversity of E. faecalis and E. faecium clones were detected circulating in the milk environments of different origins including three that have not been described previously. Some of the clones were common in different animal species as it was the case of E. faecalis-ST21, which was detected among porcine and feline isolates, or E. faecalis-ST9 among porcine and ovine ones. The sequence types found among the human isolates were only observed in milk samples of this origin. It is of interest to remark that two of the STs detected among E. faecalis strains of porcine or feline origin are included in clonal complexes (CC16 and $\mathrm{CC} 21)$ that are frequently detected in human infections in Europe [50]. In addition, it should be highlighted that the hospital-associated lineages of E. faecalis (ST21 and ST16) and E. faecium (ST5), identified in milk of porcine origin in this study, have also been detected in the pig farm environment in a recent study [51].

Several food and human isolates belonging to different species of the genus Enterococcus had been previously described as BA producers [52]. In fact, tyramine production and a variable ability to produce putrescine is a very common finding among enterococci [40]. However, to our knowledge, no histamine-producing enterococci strains have been described so far and have not been found in this work, either. Although it has been generally assumed that the ability to produce BAs is a strain-dependent characteristic, it has been recently described that tyramine biosynthesis is a species-level characteristic in E. faecalis, E. faecium and E. durans [40]. The same work suggests that putrescine biosynthesis by the agmatine deiminase pathway is also a species-level characteristic in E. faecalis. Since all the strains tested in this study showed ability to synthesize tyramine, and all the E. faecalis strains produced putrescine (Table 4), the results obtained are consistent with the fact that they are species-level characteristics. Moreover, all E. hirae and E. casseliflavus strains were also tyramine producers. Although further work is required, tyramine-production could also be a specieslevel characteristic of these species. In any case, the ability to produce tyramine is widespread in the genus Enterococcus. With respect to putrescine, the results are more variable. While all the E. faecalis were putrescine producers, only some E. faecium and E. hirae strains and none E. casseliflavus produced it. Genomic studies on E. faecium suggest that such ability could have been acquired through horizontal gene transfer [40].

The presence of BA-producing enterococci in human milk evidences the need to research if they can produce BAs in the milk, or subsequently in the gastrointestinal tract, and therefore be considered a health risk. In fact, it has been shown that tyramine-producing $E$. durans strain isolated from cheese is able to produce tyramine under conditions simulating transit through the gastrointestinal tract [53]. The milk used for the production of fermented dairy products (cows, ewes and goats) deserves also further research, since the presence of BA-producing enterococci may be responsible for the accumulation of toxic BAs concentrations in foods [54].

The E-test was used to determine the resistance pattern of the enterococcal strains against 10 clinically-relevant antimicrobials. The antibiotic resistance spectrum was wider among the E. hirae, E. faecium and, particularly, $E$. faecalis strains. In relation to the source of the samples, those isolated from porcine milk seemed to be of particular concern. Antibiotic resistance is an important factor 
for the safety evaluation of enterococci because it can be acquired and/or transferred to other bacteria by gene transfer. The major differences in the rate of resistant enterococci in porcine herds among different countries are most probably due to differences in the usage of antimicrobial agents [55].

Vancomycin-resistant enterococci (VRE) initially emerged as a relevant Public Health threat due to the use in the past of the glycopeptide avoparcin as growth promoter in animal feed. Once avoparcin was banned, the persistence of VRE was associated to co-selection of van genes and genes conferring resistance to other antibiotics (such as erythromycin) due to the intensive use of other antibiotics, such as tylosin [56]. After the ban of antibiotics as growth promoters in all European Union countries (July 1999), Aarestrup [57] speculated that occurrence of VRE among pigs would decrease in the following years. In this study, none of the strains was resistant to vancomycin, an antibiotic commonly used for infections caused by multidrug-resistant bacteria, although most of the $E$. faecalis strains isolated from porcine milk were resistant to erythromycin.

All our E. faecalis, E. faecium and E. hirae strains of food animals (porcine and ovine) were resistant to tetracycline, which has been widely used for therapy in food animals in many countries, including Spain; this usage also could have contributed to the successful persistence of tet genes. A comparison between antibiotic resistance among enterococci isolated from pigs in Sweden, Denmark and Spain showed that tet (L) and tet (S) genes were more frequently found among isolates from Spain [55].

Globally, frequent occurrences of antibiotic-resistant enterococci have been observed among food animals, and it has been suggested that these animals may be a reservoir of resistant enterococci and resistance genes capable of transferring to humans through the food chain [58]. Antimicrobial resistance genes appear to spread freely between enterococci from different reservoirs, irrespective of their apparent host association [58].

Therefore, continuous surveillance of antimicrobial resistance in enterococci from humans, animals and foods of animal origin is essential to detect emerging resistance and new infections [26]. As an example, an outbreak of infective mastitis due to $E$. faecalis was recently reported in an intensive sheep farm in Italy. Forty-five out of the 48 E. faecalis isolates showed the same multi-drug resistance pattern and had a clonal origin. This was the first reported case of ewe's mastitis caused by E. faecalis [59]. Such strains could arrive to the human food chain through the consumption of cheeses elaborated with raw ewe's milk.

Pets can also be a source of enterococci and enterococcal resistance genes to humans and other animals and vice versa. Recent results suggest that direct and frequent contact with dogs may significantly shape the composition of our microbial communities [60]. The widespread occurrence of ampicillin-resistant clones in dogs is worrying since these animals may spread such clones among humans due to the close relationships that are usually established between dogs and humans [61,62]. Due to this risk of zoonotic transfer, it has been suggested that pets used to promote the recovery of patients (pet therapy) may pose a risk to such patients if the dogs are not previously screened for the presence of such enterococcal clones [61]. Similarly, it has been reported that dogs leaving the veterinary intensive care unit (ICU) carry a very large multidrug resistant enterococcal population with capacity for horizontal gene transfer [63]. As a consequence, the authors recommended restriction of close physical contact between pets released from ICUs and their owners to avoid potential health risks [63].

\section{Conclusions}

Milk from different mammalian species may contain enterococci. The wide distribution of virulence genes and/or antibiotic resistance among E. faecalis and E. faecium strains isolated from such source indicates that they can constitute a reservoir of such traits for the infant/offspring gut and, as a consequence, a potential risk to animal and human health. In fact, some STs detected among E. faecalis strains isolated from porcine or feline samples in this study belong to clonal complexes (CC16 and CC21) frequently associated to hospital infections in Europe.

\section{Competing interests}

The authors declare that they have no competing interests.

\section{Authors' contributions}

EJ, IC, AMB, VM and, LF isolated, identified and characterized the strains. VL and MF performed the BA analysis. ML and CT carried the MLST analysis. CT, MAA and JMR designed experimental procedures. EJ, JMR, MAA and CT drafted the manuscript. All authors read, revised and approved the manuscript.

\section{Acknowledgements}

This study was supported by the CSD2007-00063 (FUN-C-FOOD, Consolider-Ingenio 2010), AGL2010-18430, AGL2010-15420 and SAF2012-35474 projects from the Ministerio de Economía y Competitividad (Spain).

\section{Author details}

'Departamento de Nutrición, Bromatología y Tecnología de los Alimentos, Universidad Complutense de Madrid, Ciudad Universitaria, Avda. Puerta de Hierro, Madrid s/n. 28040, Spain. ${ }^{2}$ Instituto de Productos Lácteos de Asturias (IPLA-CSIC), Paseo Río Linares s/n 33300, Villaviciosa, Spain. ${ }^{3}$ Departamento de Biotecnología de Alimentos, Instituto de la Grasa-CSIC, Sevilla 41012, Spain. ${ }^{4}$ Área de Bioquímica y Biología Molecular, Universidad de La Rioja, Logroño, Spain. ${ }^{5}$ Probisearch. c/Santiago Grisolía, Tres Cantos 2. 28760, Spain.

Received: 4 July 2013 Accepted: 4 December 2013

Published: 10 December 2013

\section{References}

1. Butler JE: Immunoglobulins and immunocytes in animal milks. In Mucosal Immunology. Edited by Ogra PL, Mestecky J, Lamm ME, Strober W, Bienenstock J, McGhee JR. New York: Academic Press; 1999.

2. Kehrli ME Jr, Harp JA: Immunity in the mammary gland. Vet Clin North Am Food Anim Pract 2001, 17:495-516. 
3. Newburg DS, Walker WA: Protection of the neonate by the innate immune system of developing gut and of human milk. Pediatr Res 2007, 61:2-8.

4. Stelwagen K, Carpenter E, Haigh B, Hodgkinson A, Wheeler T: Immune components of bovine colostrum and milk. J Anim Sci 2009, 87(Suppl 13):3-9.

5. Hurley WL, Theil PK: Perspectives on immunoglobulins in colostrum and milk. Nutrients 2011, 3:442-474

6. Heikkilä MP, Saris PEJ: Inhibition of Staphylococcus aureus by the commensal bacteria of human milk. J App/ Microbiol 2003, 95:471-478.

7. Martín $R$, Langa S, Reviriego C, Jiménez E, Marín ML, Xaus J, Fernández L, Rodríguez JM: Human milk is a source of lactic acid bacteria for the infant gut. J Pediatr 2003, 143:754-758.

8. Martín R, Delgado S, Maldonado A, Jiménez E, Olivares M, Fernández L, Sobrino OJ, Rodríguez JM: Isolation of lactobacilli from sow milk and evaluation of their probiotic potential. J Dairy Res 2009, 76:418-425.

9. Martín R, Olivares M, Pérez M, Xaus J, Torre C, Fernández L, Rodríguez JM: Identification and evaluation of the probiotic potential of lactobacilli isolated from canine milk. Vet J 2010, 185:193-198.

10. Albesharat R, Ehrmann MA, Korakli M, Yazaji S, Vogel RF: Phenotypic and genotypic analyses of lactic acid bacteria in local fermented food, breast milk and faeces of mothers and their babies. Syst Appl Microbiol 2011, 34:148-155.

11. Jin $L$, Hinde $K$, Tao L: Species diversity and relative abundance of lactic acid bacteria in the milk of rhesus monkeys (Macaca mulatta). $J$ Med Primatol 2011, 40:52-58.

12. Martín $\mathrm{R}$, Heilig HG, Zoetendal EG, Jiménez E, Fernández L, Smidt H, Rodríguez JM: Cultivation-independent assessment of the bacterial diversity of breast milk among healthy women. Res Microbiol 2007, 158:31-37.

13. Jiménez E, Delgado S, Maldonado A, Arroyo R, Albujar M, García N, Jariod M Fernández L, Gómez A, Rodríguez JM: Staphylococcus epidermidis: a differential trait of the fecal microbiota of breast-fed infants. BMC Microbiol 2008, 8:143.

14. Hunt KM, Foster JA, Forney L, Schutte UM, Beck DL, Abdo Z, Fox LK, Williams JE, McGuire MK, McGuire MA: Characterization of the diversity and temporal stability of bacterial communities in human milk. PLoS One 2011, 6:e21313.

15. Reviriego C, Eaton T, Martín R, Jiménez E, Fernández L, Gasson MJ, Rodríguez JM: Screening of virulence determinants in Enterococcus faecium strains isolated from breast milk. J Hum Lact 2005, 21:131-137.

16. Jiménez E, Delgado S, Fernández L, García N, Albujar M, Gómez A, Rodríguez JM: Assessment of the bacterial diversity of human colostrum and screening of staphylococcal and enterococcal populations for potential virulence factors. Res Microbiol 2008, 159:595-601.

17. Borderon JC, Lionnet C, Rondeau C, SuC Al, Laugier J, Gold F: Current aspects of fecal flora of the newborn without antibiotherapy during the first 7 days of life: Enterobacteriaceae, enterococci, staphylococci. Pathol Biol 1996, 44:416-422.

18. Jiménez E, Marín ML, Martín R, Odriozola JM, Olivares M, Xaus J, Fernández L, Rodríguez JM: Is meconium from healthy newborns actually sterile? Res Microbiol 2008, 159:187-193.

19. Manson JM, Keis S, Smith JM, Cook GM: Characterization of a vancomycinresistant Enterococcus faecalis (VREF) isolate from a dog with mastitis: further evidence of a clonal lineage of VREF in New Zealand. J Clin Microbiol 2003, 41:3331-3333.

20. Kayser FH: Safety aspects of enterococci from the medical point of view. Int J Food Microbiol 2004, 88:255-262.

21. Pomba C, Couto N, Moodley A: Treatment of a lower urinary tract infection in a cat caused by a multi-drug methicillin-resistant Staphylococcus pseudintermedius and Enterococcus faecalis. J Feline Med Surg 2010, 12:802-806

22. Eaton T, Gasson MJ: Molecular screening of Enterococcus virulence determinants and potential for genetic exchange between food and medical isolates. Appl Environ Microbiol 2001, 67:1628-1635.

23. Franz CMAP, Muscholl-Silberhorn AB, Yousif NMK, Vancanneyt M, Swings J, Holzapfel WH: Incidence of virulence factors and antibiotic resistance among enterococci isolated from food. Appl Environ Microbiol 2001, 67:4385-4389.

24. Lebreton F, Van Schaik W, Manson McGuire A, Godfrey P, Griggs A, Mazumdar V, Corander J, Cheng L, Saif S, Young S, Zeng Q, Wortman J,
Birren B, Willems RJL, Earl AM, Gilmore MS: Emergence of epidemic multidrug-resistant Enterococcus faecium from animal and commensal strains. mBio 2013, 4:e00534-13.

25. Teuber M: Veterinary use and antibiotic resistance. Curr Opin Microbio 2001, 4:493-499.

26. Hammerum AM, Lester $\mathrm{CH}$, Heuer OE: Antimicrobial-resistant enterococci in animals and meat: a human health hazard? Foodborne Pathog Dis 2010, 7:1137-1146.

27. Jensen LB, Ahrens P, Dons L, Jones RN, Hammerum AM, Aarestrup FM: Molecular analysis of Tn1546 in Enterococcus faecium isolated from animals and humans. J Clin Microbiol 1998, 36:437-442.

28. Klare I, Konstabel C, Badstubner D, Werner G, Witte W: Occurrence and spread of antibiotic resistances in Enterococcus faecium. Int J Food Microbiol 2003, 88:269-290.

29. Ladero V, Calles-Enríquez M, Fernández M, Alvarez MA: Toxicological effects of dietary biogenic amines. Cur Nutr Food Sci 2010, 6:145-156.

30. Dutka-Malen S, Evers S, Courvalin P: Detection of glycopeptides resistance genotypes and identification to the species level of clinically relevant enterococci by PCR. J Clin Microbiol 1995, 33:24-27.

31. Kullen MJ, Sanozky-Dawes RB, Crowell DC, Klaenhammer TR: Use of the DNA sequence of variable regions of the 16S rRNA gene for rapid and accurate identification of bacteria in the Lactobacillus acidophilus complex. J Appl Microbiol 2000, 89:511-516.

32. Ruiz-Barba JL, Maldonado A, Jiménez-Díaz R: Small-scale total DNA extraction from bacteria and yeast for PCR applications. Anal Biochem 2005, 347:333-335.

33. Jiménez E, Fernández L, Maldonado A, Martín R, Olivares M, Xaus J, Rodríguez JM: Oral administration of Lactobacillus strains isolated from breast milk as an alternative for the treatment of infectious mastitis during lactation. Appl Environ Microbiol 2008, 74:4650-4655.

34. Ruiz-Garbajosa P, Bonten MJ, Robinson DA, Top J, Nallapareddy SR, Torres C, Cantón R, Baquero F, Murray BE, Del Campo R, Willems RJ: Multilocus sequence typing scheme for Enterococcus faecalis reveals hospital-adapted genetic complexes in a background of high rates of recombination. J Clin Microbiol 2006, 44:2220-2228.

35. Homan WL, Tribe D, Poznanski S, Li M, Hogg M, Spalburg E, Van Embden JD, Willems RJ: Multilocus sequence typing scheme for Enterococcus faecium. J Clin Microbio/ 2002, 40:1963-1971.

36. Werner G, Fleige C, Geringer U, Van Schaik W, Klare I, Witte W: IS element IS16 as a molecular screening tool to identify hospital-associated strain of Enterococcus faecium. BMC Infect Dis 2011, 11:80.

37. López M, Cercenado E, Tenorio C, Ruiz-Larrea F, Torres C: Diversity of clones and genotypes among vancomycin-resistant clinical Enterococcus isolates recovered in a Spanish Hospital. Microb Drug Resist 2012, 18:484-491.

38. Lucas $P$, Lonvaud-funel A: Purification and partial gene sequence of the tyrosine decarboxylase of Lactobacillus brevis IOEB 9809. FEMS Microbiol Lett 2002, 211:85-89.

39. Le Jeune $C$, Lonvaud-Funel A, Ten Brink B, Hofstra H, Van der Vossen JMBM: Development of a detection system for histidine decarboxylating lactic acid bacteria based on DNA probes, PCR and activity test. J Appl Bacteriol 1995, 78:316-326.

40. Ladero V, Fernández M, Calles-Enríquez M, Sánchez-Llana E, Cañedo E, Martín MC, Alvarez MA: Is the production of the biogenic amines tyramine and putrescine a species-level trait in enterococci? Food Microbiol 2012, 30:132-138.

41. García-Moruno E, Carrascosa AV, Muñoz R: A rapid and inexpensive method for the determination of biogenic amines from bacterial cultures by thin-layer chromatography. J Food Prot 2005, 68:625-629.

42. CLSI. CLSI M100-S22: Performance Standards for Antimicrobial Susceptibility Testing; Twenty-second Informational Supplement. CLSI document M100-S22. Wayne, PA: Clinical and Laboratory Standards Institute; 2012.

43. Ramos-Trujillo E, Pérez-Roth E, Méndez-Alvarez S, Claverie-Martín F: Multiplex PCR or simultaneous detection of enterococcal genes vanA and vanB and staphylococcal genes meca, iles-2 and femB. Int Microbiol 2003, 6:113-115.

44. Perichon B, Reynolds P, Courvalin P: VanD-type glycopeptide-resistant Enterococcus faecium BM 4339. Antimicrob Agents Chemother 1997 41:2016-2018. 
45. Fines M, Perichon B, Reynolds P, Sahm DF, Courvalin P: VanE, a new type of acquired glycopeptide resistance in Enterococcus faecalis BM4405. Antimicrob Agents Chemother 1999, 43:2161-2164.

46. McKessar SJ, Berry AM, Bell JM, Turnidge JD, Paton JC: Genetic characterization of vanG. A novel vancomycin resistance locus of Enterococcus faecalis. Antimicrob Agents Chemother 2000, 44:3224-3228

47. Solís G, De Los Reyes-Gavilan CG, Fernández N, Margolles A, Gueimonde M: Establishment and development of lactic acid bacteria and bifidobacteria microbiota in breast-milk and the infant gut. Anaerobe 2010, 16:307-310.

48. Little CL, De Louvois J: Health risks associated with unpasteurized goats' and ewes' milk on retail sale in England and Wales. A PHLS Dairy Products Working Group Study. Epidemiol Infect 1999, 122:403-408.

49. Medina R, Katz M, Gonzalez S, Oliver G: Characterization of the lactic acid bacteria in ewe's milk and cheese from northwest Argentina. J Food Prot 2001, 64:559-563.

50. Kuch A, Willems RLL, Werner G, Coque TM, Hammerum AM, Sundsfjord A, Klare I, Ruiz-Garbajosa P, Simonsen GS, Van Luit-Asbroek M, Hryniewicz W, Sadowy E: Insight into antimicrobial susceptibility and population structure of contemporary human Enterococcus faecalis isolates from Europe. J Antimicrob Chemother 2012, 67:551-558.

51. Novais C, Freitas AR, Silveira E, Antunes P, Silva R, Coque TM, Peixe L: Spread of multidrug-resistant Enterococcus to animals and humans: an underestimated role for the pig farm environment. J Antimicrob Chemother 2013, 68:2746-2754.

52. Ladero V, Fernández M, Alvarez MA: Isolation and identification of tyramine-producing enterococci from human fecal samples. Can J Microbiol 2009, 55:215-218.

53. De Palencia PF, Fernández M, Mohedano ML, Ladero V, Quevedo C, Alvarez MA, López P: Role of tyramine synthesis by food-borne Enterococcus durans in adaptation to the gastrointestinal tract environment. Appl Environ Microbiol 2011, 77:699-702.

54. Linares DM, Martín MC, Ladero V, Alvarez MA, Fernández M: Biogenic amines in dairy products. Crit Rev Food Sci Nutr 2011, 51:691-703.

55. Aarestrup FM, Hasman $H$, Jensen LB, Moreno M, Herrero IA, Domínguez L, Finn $M$, Franklin A: Antimicrobial resistance among enterococci from pigs in three European countries. Appl Environ Microbiol 2002, 68:4127-4129.

56. Phillips I, Casewell M, Cox T, De Groot B, Friis C, Jones R, Nightingale C, Preston R, Waddell $J$ : Does the use of antibiotics in food animals pose a risk to human health? A critical review of published data. J Antimicrob Chemother 2004, 53:28-52.

57. Aarestrup FM: Characterization of glycopeptide-resistant Enterococcus faecium (GRE) from broilers and pigs in Denmark: genetic evidence that persistence of GRE in pig herds is associated with coselection by resistance to macrolides. J Clin Microbiol 2000, 38:2774-2777.

58. Heuer OE, Hammerum AM, Collignon P, Wegener HC: Human health hazard from antimicrobial-resistant enterococci in animals and food. Clin Infect Dis 2006, 43:911-916.

59. Sanciu G, Marogna G, Paglietti B, Cappuccinelli P, Leori G, Rappelli P: Outbreak of mastitis in sheep caused by multi-drug resistant Enterococcus faecalis in Sardinia, Italy. Epidemiol Infect 2012, 18:1-3.

60. Song SJ, Lauber C, Costello EK, Lozupone CA, Humphrey G, Berg-Lyons D, Caporaso JG, Knights D, Clemente JC, Nakielny S, Gordon JI, Fierer N, Knight $\mathrm{R}$ : Cohabiting family members share microbiota with one another and with their dogs. Elife 2013, 2:e00458.

61. Damborg P, Top J, Hendrickx AP, Dawson S, Willems RJ, Guardabassi L: Dogs are a reservoir of ampicillin-resistant Enterococcus faecium lineages associated with human infections. Appl Environ Microbiol 2009, 75:2360-2365.

62. Tremblay CL, Charlebois A, Masson L, Archambault M: Characterization of hospital-associated lineages of ampicillin-resistant Enterococcus faecium from clinical cases in dogs and humans. Front Microbiol 2013, 4:245.

63. Ghosh A, Dowd SE, Zurek L: Dogs leaving the ICU carry a very large multi-drug resistant enterococcal population with capacity for biofilm formation and horizontal gene transfer. PLoS One 2011, 6:e22451.

\section{doi:10.1186/1471-2180-13-288}

Cite this article as: Jiménez et al:: Antibiotic resistance, virulence determinants and production of biogenic amines among enterococci from ovine, feline, canine, porcine and human milk. BMC Microbiology 2013 13:288.

\section{Submit your next manuscript to BioMed Central and take full advantage of:}

- Convenient online submission

- Thorough peer review

- No space constraints or color figure charges

- Immediate publication on acceptance

- Inclusion in PubMed, CAS, Scopus and Google Scholar

- Research which is freely available for redistribution 